\title{
Fluorination, and Tunneling across Molecular Junctions
}

\section{Citation}

Liao, Kung-Ching, Carleen M. Bowers, Hyo Jae Yoon, and George M. Whitesides. 2015.

"Fluorination, and Tunneling Across Molecular Junctions." Journal of the American Chemical Society 137 (11) (March 25): 3852-3858. doi:10.1021/jacs.5b00137.

\section{Published Version}

doi:10.1021/jacs.5b00137

\section{Permanent link}

http://nrs.harvard.edu/urn-3:HUL.InstRepos:24900308

\section{Terms of Use}

This article was downloaded from Harvard University's DASH repository, and is made available under the terms and conditions applicable to Open Access Policy Articles, as set forth at http:// nrs.harvard.edu/urn-3:HUL.InstRepos:dash.current.terms-of-use\#OAP

\section{Share Your Story}

The Harvard community has made this article openly available.

Please share how this access benefits you. Submit a story.

Accessibility 


\title{
Fluorination, and Tunneling across Molecular Junctions
}

Kung-Ching Liao, ${ }^{\dagger}$ Carleen M. Bowers, ${ }^{\dagger}$ Hyo Jae Yoon,${ }^{\dagger, \dagger}$ and George M. Whitesides ${ }^{*,+, s, l}$

\author{
'Department of Chemistry and Chemical Biology, Harvard University, \\ 12 Oxford Street, Cambridge, Massachusetts 02138, United States, \\ "Department of Chemistry, Korea University, Seoul, 136-701, Korea \\ ${ }^{\S}$ Wyss Institute for Biologically Inspired Engineering, Harvard University, \\ 60 Oxford Street, Cambridge, Massachusetts 02138, United States, and \\ 'Kavli Institute for Bionano Science \& Technology, Harvard University, \\ 29 Oxford Street, Massachusetts 02138, United States
}

*Corresponding author, email: gwhitesides@gmwgroup.harvard.edu 


\section{ABSTRACT}

This paper describes the influence of substitution of fluorine for hydrogen on the rate of charge transport by hole tunneling through junctions of the form $\mathrm{Ag}^{\mathrm{TS}} \mathrm{O}_{2} \mathrm{C}\left(\mathrm{CH}_{2}\right)_{\mathrm{n}}\left(\mathrm{CF}_{2}\right)_{\mathrm{m}} \mathrm{T} / / \mathrm{Ga}_{2} \mathrm{O}_{3} / \mathrm{EGaIn}$, where $\mathrm{T}$ is methyl $\left(\mathrm{CH}_{3}\right)$ or trifluoromethyl $\left(\mathrm{CF}_{3}\right)$. Alkanoate-based self-assembled monolayers (SAMs) having perfluorinated groups $\left(\mathrm{R}^{\mathrm{F}}\right)$ show current densities that are lower (by factors of 20-30) than those of the homologous hydrocarbons $\left(\mathrm{R}^{\mathrm{H}}\right)$, while the attenuation factors of the simplified Simmons equation for methylene $\left(\beta=1.05 \pm 0.02 \mathrm{n}_{\mathrm{CH}_{2}}{ }^{-1}\right)$ and difluoromethylene $(\beta$ $=1.15 \pm 0.02 \mathrm{n}_{\mathrm{CF}_{2}}^{-1}$ ) are similar (although the value for $\left(\mathrm{CF}_{2}\right)_{\mathrm{n}}$ is statistically significantly larger). A comparative study focusing on the terminal fluorine substituents in SAMs of $\omega$-tolyl and phenyl alkanoates suggests that the $\mathrm{C}-\mathrm{F} / / \mathrm{Ga}_{2} \mathrm{O}_{3}$ interface is responsible for the lower tunneling currents for $\mathrm{CF}_{3}$. The decrease in the rate of charge transport in SAMs with $\mathrm{R}^{\mathrm{F}}$ groups (relative to homologous $\mathrm{R}^{\mathrm{H}}$ groups) is plausibly due to an increase in the height of the tunneling barrier at the $\mathrm{T} / / \mathrm{Ga}_{2} \mathrm{O}_{3}$ interface, and/or to weak van der Waals interactions at that interface. 


\section{INTRODUCTION}

Studies of charge tunneling through metal-molecule-metal (MMM) junctions have focused predominately on testing hypotheses that correlate the chemical and electronic structure of the molecules with current densities (or in the case of single-molecule studies, with currents). A convenient, semi-quantitative theoretical framework around which to organize trends relating measurable parameters (e.g., the length of a $\left(\mathrm{CH}_{2}\right)_{\text {n }}$ group) to experimental data (e.g., current densities at a fixed applied voltage) has been the simplified Simmons equation (eq. 1). ${ }^{1-11}$ In this

$$
J(V)=J_{0}(V) e^{-\beta d}=J_{0}(V) 10^{-\frac{\beta d}{2.303}}
$$

approximation, the tunneling barrier is approximated as rectangular, with width $d$, and a height related to the attenuation factor $\beta .{ }^{12,13} J(V)$ is current density $\left(\mathrm{A} / \mathrm{cm}^{2}\right)$ at an applied bias $V$, and $J_{0}$ is loosely interpretable as the injection current for a hypothetical junction with $d=0$. Changes in the topography of the barrier, the energies of the frontier orbitals, molecular dipoles, and polarizabilities of the insulating molecules in the junctions, are ignored or considered as part of $J_{0}{ }^{14-18}$

We have studied this type of system using SAM-based junctions of the structure $\mathrm{Au}^{\mathrm{TS}}$ or $\mathrm{Ag}^{\mathrm{TS}} / \mathrm{A}-\mathrm{R}_{1}-\mathrm{M}-\mathrm{R}_{2}-\mathrm{T} / / \mathrm{Ga}_{2} \mathrm{O}_{3} / \mathrm{EGaIn}$; previous papers describe these studies. ${ }^{11,19-25}$ We have used a variety of polar, aromatic, and aliphatic groups for the "anchoring" (A), "middle" (M), and “terminal" (T) groups. One of the unexpected implications of these studies has been that increasing the strength of the interaction across the $\mathrm{T} / / \mathrm{Ga}_{2} \mathrm{O}_{3}$ interface does not seem to increase the tunneling current density of $n$-alkyl SAMs, ${ }^{20}$ decreasing this strength does, however, seem to decrease the tunneling current. The topography of these tunneling barriers seems to be dominated by the electronic structure of the insulating alkyl chains. A theoretical study by Nijhuis and Zhang calculated that the $\mathrm{T} / / \mathrm{Ga}_{2} \mathrm{O}_{3}$ interface was the highest region in the tunneling barrier. ${ }^{26}$ 
One possible, testable hypothesis based on these experimental and theoretical studies might be that decreasing the strength of the $\mathrm{T} / / \mathrm{Ga}_{2} \mathrm{O}_{3}$ interface might decrease the tunneling current density by increasing the height of the tunneling barrier at its highest point (i.e., at that interface).

The work we describe here was designed to test this possibility by replacing $\mathrm{C}-\mathrm{H}$ bonds in the terminal group $\mathrm{T}$ with $\mathrm{C}-\mathrm{F}$ bonds, and comparing tunneling current densities. Replacing hydrogen ( $\mathrm{C}-\mathrm{H}$ bonds) with less polarizable fluorine (C-F bonds) often changes the structural, chemical, and electronic properties of hydrocarbons. ${ }^{27,28}$ For example, electronegative fluorine influences the frontier orbital energy of alkanes, lowers their surface energy and polarizability, and disrupts interchain packing and van der Waals interactions between chains in a SAM. ${ }^{29,30}$ We explored the influence of the extent of fluorination of $n$-alkyl SAMs on the rate of charge transport across large-area junctions of the form $\mathrm{Ag}^{\mathrm{TS}} \mathrm{O}_{2} \mathrm{C}\left(\mathrm{CH}_{2}\right)_{\mathrm{n}}\left(\mathrm{CF}_{2}\right)_{\mathrm{m}} \mathrm{T} / / \mathrm{Ga}_{2} \mathrm{O}_{3} / \mathrm{EGaIn}(\mathrm{n}, \mathrm{m}=$ $0,2,4,6,8)$ at $\pm 0.5 \mathrm{~V}$. We varied the number of methylene $\left(\mathrm{CH}_{2}\right)$ and difluoromethylene $\left(\mathrm{CF}_{2}\right)$ groups in the backbone of the SAM, and changed the terminal function groups (T) of the SAM from $\mathrm{H}$ to $\mathrm{F}$, and from $\mathrm{CH}_{3}$ to $\mathrm{CF}_{3}$, in order to test two possibilities: i) In the backbone of the molecules, $\mathrm{CH}_{2}$ and $\mathrm{CF}_{2}$ might contribute differently to the height of the tunneling barrier, since electronegative fluorine substituents could lower the energy of the highest occupied molecular orbital (HOMO) of the $n$-alkyl SAMs, increase $\beta$, and decrease the tunneling current density. ii) In the terminal group $\mathrm{T}$, replacing $\mathrm{C}-\mathrm{H}$ bonds with $\mathrm{C}-\mathrm{F}$ bonds might decrease the strength of the van der Waals interaction across the $\mathrm{T} / / \mathrm{Ga}_{2} \mathrm{O}_{3}$ interface, raise the tunneling barrier in this region, decrease $J_{0}(V)$, and decrease the tunneling current density.

Replacing $\mathrm{C}-\mathrm{H}$ bonds with $\mathrm{C}-\mathrm{F}$ bonds in the terminal group $\mathrm{T}$ did, in fact, significantly lower the tunneling current density in a number of these compounds. Our specific focus in this work concerned the mechanism and origin of this effect. Experimentally, we observed that $\mathrm{CH}_{2}$ 
and $\mathrm{CF}_{2}$ contribute similarly (although perhaps distinguishably; see below) to the effective height of the tunneling barrier, and that the $\mathrm{C}-\mathrm{F} / / \mathrm{Ga}_{2} \mathrm{O}_{3}$ interface is responsible for low tunneling currents of some fluorinated hydrocarbons (e.g., perfluoroalkanes). The values of the attenuation factor, $\beta$ in eq. 1 , for $\mathrm{CH}_{2}\left(\beta=1.05 \pm 0.02 \mathrm{n}_{\mathrm{CH}_{2}}{ }^{-1}\right)$ and $\mathrm{CF}_{2}\left(\beta=1.15 \pm 0.02 \mathrm{n}_{\mathrm{CF}_{2}}{ }^{-1}\right)$ are similar, although distinguishable. The extrapolated current density (at $-0.5 \mathrm{~V}$ ) of the perfluorinated $n$ -

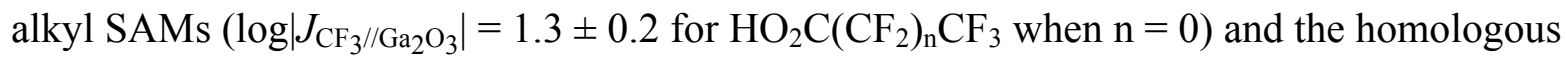
hydrocarbons $\left(\log \left|J_{\mathrm{CH}_{3} / / \mathrm{Ga}_{2} \mathrm{O}_{3}}\right|=2.8 \pm 0.2\right)$ differ significantly and in a way that suggests that the difference is primarily attributable to the $\mathrm{T} / / \mathrm{Ga}_{2} \mathrm{O}_{3}$ interface. We observed similar offsets of $J_{0}$ for para-substituted $\left(\mathrm{T}=\mathrm{CH}_{3}\right.$ or $\left.\mathrm{CF}_{3}\right) \omega$-tolyl-alkanoates $\left(\mathrm{HO}_{2} \mathrm{C}\left(\mathrm{CH}_{2}\right)_{n}\left(\mathrm{C}_{6} \mathrm{H}_{4}\right) \mathrm{T}\right)$ and oligophenyl carboxylates $\left(\mathrm{HO}_{2} \mathrm{C}\left(\mathrm{C}_{6} \mathrm{H}_{4}\right)_{n} \mathrm{~T}\right)$. In all of these compounds, the rates of charge transport across the $\mathrm{C}-\mathrm{F} / / \mathrm{Ga}_{2} \mathrm{O}_{3}$ interface are consistently lower by factors of $25-30$ than those across the C$\mathrm{H} / / \mathrm{Ga}_{2} \mathrm{O}_{3}$ interface.

\section{BACKGROUND}

SAMs with perfluorinated groups $\left(\mathrm{R}^{\mathrm{F}}\right)$ show structural and electronic properties that are different than those of the homologous hydrocarbons $\left(\mathrm{R}^{\mathrm{H}}\right)$. The aliphatic $\mathrm{C}$-F bond is $\sim 1.4 \AA$ in length and has a dipole moment of about 1.4 Debye; the aliphatic C-H bond is $\sim 1.1 \AA$ in length, and has a dipole moment of 0.3 Debye. The van der Waals radius of fluorine $(1.47 \AA)$ is larger than that of hydrogen $(1.2 \AA) .{ }^{31,32}$ Fluorination of hydrocarbons raises the ionization potential of linear hydrocarbons (fluorocarbons) from $10 \mathrm{eV}$ to $17 \mathrm{eV},{ }^{33}$ lowers the HOMO energy by $1.0-1.5 \mathrm{eV}$ (and also increases the HOMO-LUMO gap), ${ }^{34}$ and shifts the UV absorption band toward higher energy (approximately from $122 \mathrm{~nm}$ to $187 \mathrm{~nm}$ ); ${ }^{35}$ fluorination also changes the gas solubility, and the boiling and melting points of hydrocarbons, in ways compatible with weaker intermolecular forces between fluorocarbons than between hydrocarbons ${ }^{35}$ Fluorocarbons, 
which have lower polarizability than hydrocarbons, ${ }^{32,34}$ are functional groups that have been used to manipulate the chemical and electronic properties of metals and metal oxides. ${ }^{36-41}$ SAMs with $\mathrm{R}^{\mathrm{F}}$ groups exhibit both hydrophobic and lipophobic properties, and are more thermally stable and chemically inert than SAMs based on analogous hydrocarbons $\left(\mathrm{R}^{\mathrm{H}}\right) \cdot{ }^{36,42,43}$ In contrast to $\mathrm{R}^{\mathrm{H}}$ chains $\left(-\left(\mathrm{CH}_{2}\right)_{\mathrm{n}}-\right)$, which generally show linear, trans-extended packing in SAMs, the backbone of $\mathrm{R}^{\mathrm{F}}$ chains $\left(-\left(\mathrm{CF}_{2}\right)_{\mathrm{n}}-\right)$ form a helix-like structure that creates a slightly larger footprint for the individual $\mathrm{R}^{\mathrm{F}}$ molecules. ${ }^{44-46}$ Both $\mathrm{R}^{\mathrm{H}}$ and $\mathrm{R}^{\mathrm{F}}$ molecules form densely packed SAMs.

SAMs have been used to modify the electronic properties of the interface between the electrodes and the organic active layers in organic electronics. ${ }^{41}$ For example, Blom et al. demonstrated that SAMs of $n$-alkanethiols can be used to decrease the work functions of gold and silver, whereas SAMs of perfluorinated $n$-alkanethiols can be used to increase these work functions (the $\mathrm{R}^{\mathrm{H}}$ and $\mathrm{R}^{\mathrm{F}}$ groups introduce opposite dipoles at the surface of the electrodes). ${ }^{47}$ Cho and Tao reported that the work function of silver and aluminum can also be tuned using carboxylate-based SAMs $;^{48}$ depending on the length and the extent of fluorination in the structure of $n$-alkanoates, the work function of SAM-modified silver can be shifted from $4.6 \mathrm{eV}$ (bare $\mathrm{Ag}$ ) to $5.7 \mathrm{eV}$ ( $\mathrm{R}^{\mathrm{F}}$-bound $\mathrm{Ag}$ ). ${ }^{48-50}$ This work also confirmed that the carboxylate anchoring group binds in a bidentate form to the surface of $\mathrm{Ag}$ (where a layer of native silver oxide possibly exists at the interface between the metal and the carboxylate) with an angle of inclination of the $\mathrm{R}^{\mathrm{F}}$ chain of $c a .28^{\circ}$ to the surface normal. ${ }^{48}$

\section{RESULTS AND DISCUSSION}

We prepared SAMs on template-stripped silver using commercially available fluorinated $n$-alkanoic acids, following a previously reported procedure (Figure 1a) ${ }^{48}$ SAMs were formed by 
introducing freshly prepared $\mathrm{Ag}^{\mathrm{TS}}$ substrates ${ }^{51}$ into $1 \mathrm{mM}$ solutions of fluorinated alkanoic acids in $n$-hexadecane for 10 minutes; further immersion (up to 48 hours) did not change either the static contact angle of water $\left(\sim 121 \pm 5^{\circ}\right)$ on the SAMs, or the yields of working junctions. Following incubation at room temperature (and directly before electrical measurements), we rinsed the SAM-bound $\mathrm{Ag}$ substrates three times with anhydrous hexane ( $1 \mathrm{~mL}$ each time) to remove the residual hexadecane from the surface of $\mathrm{R}^{\mathrm{F}}$-bound silver, and dried the substrates under a gentle stream of nitrogen. We measured $J(V)$ for junctions of the structure $\mathrm{Ag}^{\mathrm{TS}} \mathrm{O}_{2} \mathrm{C}\left(\mathrm{CH}_{2}\right)_{\mathrm{n}}\left(\mathrm{CF}_{2}\right)_{\mathrm{m}} \mathrm{T} / / \mathrm{Ga}_{2} \mathrm{O}_{3} / E G a I n$ using what we call "selected" conical EGaIn tips ${ }^{4}$ (with a geometrical contact area of $\sim 1800 \mu \mathrm{m}^{2}$ ) over the range of $\pm 0.5 \mathrm{~V}$ as a function of the number of $\mathrm{CH}_{2}$ and/or $\mathrm{CF}_{2}$ units (where $\mathrm{n}, \mathrm{m}=0,2,4,6,8$ and $\mathrm{T}=\mathrm{CH}_{3}$ or $\mathrm{CF}_{3}$ ). We and others have discussed the details of the EGaIn electrode extensively. ${ }^{11,52-54}$ (See the Supporting Information for additional details on the measurement procedure and data analysis).

Although the structure and surface energy of $\mathrm{R}^{\mathrm{F}}$ and $\mathrm{R}^{\mathrm{H}} \mathrm{SAMs}$ differ significantly, the contributions of $\mathrm{CH}_{2}$ and $\mathrm{CF}_{2}$ groups to the height of the tunneling barrier are apparently slightly different in their contributions to the value of $\beta$. Figure $1 \mathrm{~b}$ shows a plot of $\log |J(-0.5 \mathrm{~V})|$ versus the number of $\mathrm{CH}_{2}$ and/or $\mathrm{CF}_{2}$ groups for junctions comprising SAMs of $2 \mathrm{H}, 2 \mathrm{H}, 3 \mathrm{H}, 3 \mathrm{H}$ perfluoroalkanotes, perfluoroalkanotes, and previously studied $n$-alkanoates. ${ }^{19}$ Because the $\mathrm{R}^{\mathrm{F}}$ and $\mathrm{R}^{\mathrm{H}} \mathrm{SAMs}$ may adopt different molecular structures (e.g., helical $\left(\mathrm{CF}_{2}\right)_{\mathrm{n}}$ versus transextended $\left(\mathrm{CH}_{2}\right)_{\mathrm{n}}$ conformations), we do not estimate the width of the tunneling barrier ( $d$ in eq.1) from an estimation of the extended length of the molecules in $\mathrm{nm}$, but instead empirically from the number of carbon atoms being considered. The current density across junctions containing fluorinated SAMs decreased exponentially with an increasing length of the fluorinated $n$-alkyl chain (Figure S1 summarizes histograms of $\log |J(-0.5 \mathrm{~V})|$ derived from the measurements). 
None of these junctions rectified current. A linear-least squares fitting for each series yielded a slope $\left(\mathrm{R}^{2} \geq 0.99\right)$ and an intercept at the $y$ axis.

Values of $\beta$ for changes in the length of $\left(\mathrm{CF}_{2}\right)_{\mathrm{n}}$ chain $\left(\beta=1.15 \pm 0.02 \mathrm{n}_{\mathrm{CF}_{2}}{ }^{-1}\right)$ and corresponding $\left(\mathrm{CH}_{2}\right)_{\mathrm{n}}$ chains $\left(\beta=1.05 \pm 0.02 \mathrm{n}_{\mathrm{CH}_{2}}{ }^{-1}\right)$ were apparently slightly different in SAMs of perfluoroalkanoates and $n$-alkanoates. In the Simmons equation, ${ }^{12,13,55,56}$ the value of $\beta$ is determined by an effective height of the barrier $(\varphi, \mathrm{eV})$; for hole tunneling, ${ }^{2,3} \varphi$ (assumed to be a simple rectangle) is the difference in energy $(\mathrm{eV})$ between the Fermi level $\left(\mathrm{E}_{F}\right)$ of the electrode and the HOMO of the molecule. Although the chemical and electronic properties of $\mathrm{R}^{\mathrm{F}}$ and $\mathrm{R}^{\mathrm{H}}$ chains are different, we are not able to attribute (with confidence) the small difference ( $c a .10 \%)$ between the values of $\beta$ for $\mathrm{CF}_{2}$ and $\mathrm{CH}_{2}$ to differences in their frontier orbital energies. It is possible that $\mathrm{CF}_{2}$ has a lower $\mathrm{HOMO}$ energy (by $1 \mathrm{eV}$ ) than that of $\mathrm{CH}_{2},{ }^{34}$ but the work function of $\mathrm{R}^{\mathrm{F}}$-bound $\mathrm{Ag}$ is also increased by approximately $1 \mathrm{eV}$ (relative to bare $\mathrm{Ag}$ ). ${ }^{48}$ The simultaneous shifts in the HOMO energy of molecules and the work function of the SAM-bound electrode make $\varphi$ of $\mathrm{CF}_{2}$ and $\mathrm{CH}_{2}$ indistinguishable (to the level of granularity that we can detect). A study using inelastic electron tunneling spectroscopy reported a similar conclusion. ${ }^{29}$

The $\mathbf{C}-\mathbf{F} / / \mathrm{Ga}_{2} \mathrm{O}_{3}$ interface is responsible for low tunneling currents of $\mathbf{R}^{\mathrm{F}} \mathrm{SAMs}$. The intercepts (when $\mathrm{n}=0$; Figure $1 \mathrm{~b}$ ) represent the extrapolated value of the log-current density $\left(\log \left|J_{0}\right|\right)$ for junctions having only the carboxylate anchoring group (A), the distal methyl or trifluoromethyl group (T), and their interfaces with the bottom and top electrodes. We refer to the current density for a junction containing $\mathrm{CH}_{3} / / \mathrm{Ga}_{2} \mathrm{O}_{3}$ interface as $J_{0, \mathrm{CH}_{3} / / \mathrm{Ga}_{2} \mathrm{O}_{3}}$

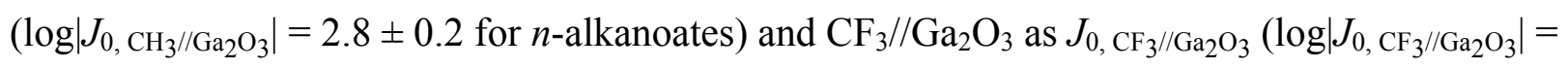
$1.3 \pm 0.2$ for perfluoroalkanoates and $\log \left|J_{0, \mathrm{CF}_{3} / / \mathrm{Ga}_{2} \mathrm{O}_{3} \mid}\right|=1.5 \pm 0.3$ for $2 \mathrm{H}, 2 \mathrm{H}, 3 \mathrm{H}, 3 \mathrm{H}-$ perfluoroalkanoates; Table 1). The difference in $J_{0}$ (up to a factor of $\sim 30$ ) between the $\mathrm{R}^{\mathrm{F}}$ and $\mathrm{R}^{\mathrm{H}}$ 
SAMs, and the similarity in $\beta$ for compounds that interchange $\mathrm{CH}_{2}$ and $\mathrm{CF}_{2}$ groups, suggest that the $\mathrm{C}-\mathrm{F} / / \mathrm{Ga}_{2} \mathrm{O}_{3}$ interface is responsible for the reduction in $J_{0}$. To verify the influence of the $\mathrm{C}-\mathrm{F} / / \mathrm{Ga}_{2} \mathrm{O}_{3}$ interface on the rates of charge transport, we replaced only the distal $\mathrm{CH}_{3}$ with a $\mathrm{CF}_{3}$

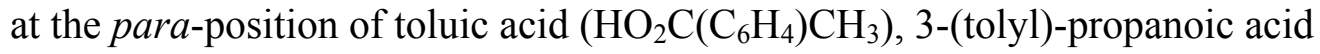
$\left(\mathrm{HO}_{2} \mathrm{C}\left(\mathrm{CH}_{2}\right)_{2}\left(\mathrm{C}_{6} \mathrm{H}_{4}\right) \mathrm{CH}_{3}\right)$, and 4'-methyl-biphenyl-4-carboxylic acid $\left(\mathrm{HO}_{2} \mathrm{C}\left(\mathrm{C}_{6} \mathrm{H}_{4}\right)_{2} \mathrm{CH}_{3}\right)$. We do not expect this structural change (i.e., the substitution of $\mathrm{CH}_{3}$ for a $\mathrm{CF}_{3}$ at the para-position) to influence significantly the order and packing of the SAM. The C-F bonds $(\sim 1.4 \AA)$ are $\sim 30 \%$ longer than $\mathrm{C}-\mathrm{H}$ bonds $(\sim 1.1 \AA)$, but we estimate that this difference in length (and a consequent change in the width of the barrier) would have only a small effect on $J\left(V\right.$ ) (by a factor of $\sim 1.3$ ); ${ }^{57}$ the surface energy (hydrophobicity or polarizability) of the SAM, however, may change due to the organization of the $\mathrm{C}-\mathrm{F}$ bonds. ${ }^{30}$

The results confirm the hypothesis that the interaction between the distal fluorinated substituents with the $\mathrm{Ga}_{2} \mathrm{O}_{3}$ influences the shape of the barrier of the $\mathrm{T} / / \mathrm{Ga}_{2} \mathrm{O}_{3}$ interface and reduces the rate of charge transport across the junctions. Figure 2 shows histograms of $\log |J(-0.5 \mathrm{~V})|$ of $\mathrm{HO}_{2} \mathrm{C}\left(\mathrm{CH}_{2}\right)_{2}\left(\mathrm{C}_{6} \mathrm{H}_{4}\right) \mathrm{T}$ and $\mathrm{HO}_{2} \mathrm{C}\left(\mathrm{C}_{6} \mathrm{H}_{4}\right)_{\mathrm{m}} \mathrm{T}$, where $\mathrm{m}=1,2$ and $\mathrm{T}=\mathrm{CH}_{3}$ (black traces) or $\mathrm{CF}_{3}$ (blue traces). These three pairs of compounds show a consistent difference of $\Delta \log |J|_{\text {mean }} \sim 1.5$ between SAMs terminated with $\mathrm{T}=\mathrm{CH}_{3}$ and $\mathrm{CF}_{3}$; that is, the rates of charge transport across junctions having a $\mathrm{CF}_{3} / / \mathrm{Ga}_{2} \mathrm{O}_{3}$ interface are lower by a factor of $\sim 30$ than those across molecularly analogous junctions with a $\mathrm{CH}_{3} / / \mathrm{Ga}_{2} \mathrm{O}_{3}$ interface.

The nature of the $\mathrm{T} / / \mathrm{Ga}_{2} \mathrm{O}_{3}$ interface does not influence the attenuation of current across other components in the junctions. We studied another series of junctions, comprising SAMs of $\omega$-phenyl-alkanoic acids $\left(\mathrm{HO}_{2} \mathrm{C}\left(\mathrm{CH}_{2}\right)_{\mathrm{n}}\left(\mathrm{C}_{6} \mathrm{H}_{4}\right) \mathrm{T}\right.$, here $\mathrm{m}=0,2,4$ and $\mathrm{T}=\mathrm{H}$ or F; Figure 3a), to determine the influence of the $\mathrm{C}-\mathrm{F} / / \mathrm{Ga}_{2} \mathrm{O}_{3}$ interface on $\beta$ across the rest of the molecule 
in the junction (i.e., the methylene groups in the SAMs). Figure $3 \mathrm{~b}$ shows a plot of $\log |J(-0.5 \mathrm{~V})|$ versus the number of $\mathrm{CH}_{2}$ groups in the structure of $\mathrm{HO}_{2} \mathrm{C}\left(\mathrm{CH}_{2}\right)_{\mathrm{n}}\left(\mathrm{C}_{6} \mathrm{H}_{4}\right) \mathrm{T}$ with $\mathrm{T}=\mathrm{H}$ (filled cubes) or F (hollow cubes). Linear-least square fits for these two series give indistinguishable values of $\beta$ for changes in the length of the polymethylene chain $\left(\mathrm{CH}_{2}\right)_{\mathrm{n}}\left(\beta=0.98-0.99 \mathrm{n}_{\mathrm{CH}_{2}}{ }^{-1}\right)$, but distinct intercepts (at the $y$ axis) when $\mathrm{n}=0$. The indistinguishable values of $\beta$ agree with observations made by us and others in alkane-based systems, ${ }^{11,19,58-60}$ and show that the terminal $\mathrm{C}-\mathrm{F} / / \mathrm{Ga}_{2} \mathrm{O}_{3}$ interface does not influence the barrier height associated with a polymethylene segment in the interior of the SAM. The difference of the intercepts $(\Delta \log |J(-0.5 \mathrm{~V})|=1.2)$ in Figure $3 b$ (and the difference in the values of log-current densities in Figure 4) also agrees with our observation of low tunneling currents for SAMs terminated with a $\mathrm{CF}_{3}$ group (Figure 1 and Table 1). The results from these compounds demonstrate that the $\mathrm{C}-\mathrm{F} / / \mathrm{Ga}_{2} \mathrm{O}_{3}$ interface is part of the tunneling barrier, as expected from prior work, ${ }^{20}$ and is—in these compounds-responsible for the reduction in $J_{0}$.

We have explored previously the influence of terminal groups $\mathrm{T}$-ranging from aliphatic, simple aromatic, polar, and Lewis-acidic and -basic functional groups that form van der Waals, hydrogen, and/or ionic interactions at the $\mathrm{T} / / \mathrm{Ga}_{2} \mathrm{O}_{3}$ interface-on the shape of the tunneling barrier. ${ }^{20-22}$ A comparison of rates of charge transport to $n$-alkanes (using a standard set of reference compounds) suggested that increasing the strength of the interaction—from a van der Waals interface to a hydrogen-bonded and/or ionically bonded interface — did not significantly influence the height of the barrier at the $\mathrm{T} / / \mathrm{Ga}_{2} \mathrm{O}_{3}$ interface. Among these molecules, SAMs of $\mathrm{S}\left(\mathrm{CH}_{2}\right)_{4} \mathrm{CONH}\left(\mathrm{CH}_{2}\right)_{2} \mathrm{CF}_{3}$ seemed to be the exception; we measured a lower $J(V)$ (by a factor of 3) relative to that of a standard $n$-alkanethiolate of similar length. ${ }^{21}$ We do not entirely understand why this factor is not the factor of 20-30 measured here, but note that the terminal 
group of $\mathrm{S}\left(\mathrm{CH}_{2}\right)_{4} \mathrm{CONH}\left(\mathrm{CH}_{2}\right)_{2} \mathrm{CF}_{3}$ in contact with the $\mathrm{Ga}_{2} \mathrm{O}_{3} / \mathrm{EGaIn}$ electrode might not be exclusively trifluoromethyl $\left(\mathrm{CF}_{3}\right)$. Our recent study of odd/even effects ${ }^{25}$ suggested that the structure of the terminal group in contact with the $\mathrm{Ga}_{2} \mathrm{O}_{3}$ might be closer to trifluoroethyl $\left(-\mathrm{CH}_{2} \mathrm{CF}_{3}\right)$ than to $\mathrm{CF}_{3}$, due to changes in the supramolecular structure of the SAM; this difference could introduce a $\mathrm{C}-\mathrm{H} / / \mathrm{Ga}_{2} \mathrm{O}_{3}$ contact at the interface. This present study of perfluorinated SAMs $\left(\mathrm{O}_{2} \mathrm{C}\left(\mathrm{CF}_{2}\right)_{\mathrm{n}} \mathrm{CF}_{3}\right)$, in the context of the present results, excludes the possibility of a mixed $\mathrm{C}-\mathrm{F}(\mathrm{H}) / / \mathrm{Ga}_{2} \mathrm{O}_{3}$ interface.

\section{CONCLUSIONS}

The key experimental result of this study is its demonstration that changing a terminal methyl $\left(\mathrm{CH}_{3}\right)$ group to a trifluoromethyl $\left(\mathrm{CF}_{3}\right)$ group decreases the rate of tunneling by a factor of 20-30, but changing an internal methylene $\left(\mathrm{CH}_{2}\right)$ to a difluoromethylene $\left(\mathrm{CF}_{2}\right)$ has only a small effect. It leads to the interesting suggestion that although it may not be possible to increase the tunneling current by lowering the effective height of the barrier at the $\mathrm{T} / / \mathrm{Ga}_{2} \mathrm{O}_{3}$ interface by increasing the strength of the interaction between the group $\mathrm{T}$ and $\mathrm{Ga}_{2} \mathrm{O}_{3}$, it may be possible to decrease the rate of tunneling by raising the height of that part of the barrier by decreasing the strength of this interaction.

We have compared tunneling currents of partially and completely fluorinated $n$ alkanoates and the homologous $n$-alkanoates using EGaIn-based junctions. We conclude that i) the influence of $\mathrm{CH}_{2}$ and $\mathrm{CF}_{2}$ groups on the shape of the tunneling barrier is similar (although marginally distinguishable by these measurements). This observation suggests that fluorination in the methylene groups of $n$-alkanes has only a small effect (at the scale that we can detect) on the apparent height $(\varphi)$ (as approximated by eq. 1) of the tunneling barrier, perhaps because both 
the HOMO energy of $\mathrm{R}^{\mathrm{F}}$ SAMs and the work function of $\mathrm{R}^{\mathrm{F}}$-bound $\mathrm{Ag}$ are shifted, in ways that partially cancel. ii) By contrast, fluorination of the terminal group has a large (x 20-30) effect and decreases tunneling currents. We conclude that the $\mathrm{C}-\mathrm{F} / / \mathrm{Ga}_{2} \mathrm{O}_{3}$ interface is the part of the tunneling barrier that is responsible for the reduction of rates of charge transport across $\mathrm{R}^{\mathrm{F}}$ SAMs.

The mechanism(s) of reduction of tunneling transport across the $\mathrm{R}^{\mathrm{F}} / / \mathrm{Ga}_{2} \mathrm{O}_{3} / \mathrm{EGaIn}$ interface (relative to a structurally similar $\mathrm{R}^{\mathrm{H}} / / \mathrm{Ga}_{2} \mathrm{O}_{3} / \mathrm{EGaIn}$ interface) is still not uniquely defined by the available data. We suggest four plausible mechanisms: Two (i and ii) are less plausible, and iii) and iv) are difficult to differentiate. i) Change in Work Function: C-F bonds or fluorocarbons do not have the highest dipole moment among polar groups (including cyanide and nitro groups) in our prior study, ${ }^{21}$ but these polar terminal groups in alkyl-based SAMs do not significantly influence tunneling currents. Thus a high dipole moment (and perhaps, in consequence, a high surface potential) does not appear to be the origin of the decrease in tunneling current density observed on converting a terminal $\mathrm{CH}_{3}$ group to a $\mathrm{CF}_{3}$ group. ii) Relative Size of Fluorocarbons and Hydrocarbons: Although the C-F bonds $(\sim 1.4 \AA)$ are considerably longer than $\mathrm{C}-\mathrm{H}$ bonds $(\sim 1.1 \AA)$, we estimated that this difference in length (and thus in the width of the barrier) would only have a small effect on $J(V)$ (a factor of $\sim 1.3$ ). Thus the greater "size" of terminal fluorinated groups (relative to $\mathrm{CH}_{3}$ group) does not seem to be responsible to the decreased rates of tunneling for $\mathrm{T}=\mathrm{CF}_{3}$. iii) Weak Electronic Interactions at the Interface: Fluorine has the lowest polarizability $\left(0.56 \times 10^{-24} \mathrm{~cm}^{3}\right)$ of all elements, ${ }^{31}$ and this low polarizability might decrease the strength of the van der Waals interactions across the interface, decrease the magnitude of electronic coupling between the $\mathrm{R}^{\mathrm{F}} \mathrm{SAMs}$ and the top electrodes, and therefore, reduce the rates of tunneling across the interface. iv) Poor Wetting at the Interface: Fluorocarbons are both hydrophobic and lipophobic, but the $\mathrm{Ga}_{2} \mathrm{O}_{3}$ layer of the top 
EGaIn electrode is hydrophilic. ${ }^{54}$ This difference in surface energy could lead to weak physical contact (wetting) of the C-F surface by the flexible $\mathrm{Ga}_{2} \mathrm{O}_{3}$ surface membrane at the $\mathrm{C}-\mathrm{F} / / \mathrm{Ga}_{2} \mathrm{O}_{3}$ interface, and result in a lower area of effective electrical contact for a $\mathrm{F} / / \mathrm{Ga}_{2} \mathrm{O}_{3}$ interface than for a $\mathrm{H} / / \mathrm{Ga}_{2} \mathrm{O}_{3}$ interface. ${ }^{11}$

\section{ASSOCIATED CONTENT}

\section{Supporting information}

Detailed experimental procedure, histograms of current densities, and summary of junction measurements. This material is available free of charge via the Internet at http://pubs.acs.org.

\section{AUTHOR INFORMATION}

Corresponding Author

gwhitesides@gmwgroup.harvard.edu

Notes

The authors declare no competing financial interest.

\section{ACKNOWLEDGMENTS}

This work was supported by a subcontract from Northwestern University from the United States Department of Energy (DE-SC0000989). The DOE grant from Northwestern University also supported the salary for K.-C.L. and C.M.B. H.J.Y. acknowledges the financial support from Basic Science Research Program through the National Research Foundation of Korea (NRF) funded by the Ministry of Science ICT \& Future Planning (NRF-2014R1A1A1002938) and the Ministry of Education (NRF20100020209). 


\section{REFERENCES}

(1) Fan, F.-R. F.; Yang, J.; Cai, L.; Price, D. W.; Dirk, S. M.; Kosynkin, D. V.; Yao, Y.; Rawlett, A. M.; Tour, J. M.; Bard, A. J. J. Am. Chem. Soc. 2002, 124, 5550.

(2) Salomon, A.; Cahen, D.; Lindsay, S.; Tomfohr, J.; Engelkes, V. B.; Frisbie, C. D. Adv. Mater. 2003, 15, 1881 .

(3) Tran, E.; Grave, C.; Whitesides, G. M.; Rampi, M. A. Electrochim. Acta 2005, 50, 4850 .

(4) Joachim, C.; Ratner, M. A. Proc. Natl. Acad. Sci. USA 2005, 102, 8801.

(5) Venkataraman, L.; Klare, J. E.; Nuckolls, C.; Hybertsen, M. S.; Steigerwald, M. L. Nature 2006, 442, 904.

(6) Lindsay, S. M.; Ratner, M. A. Adv. Mater. 2007, 19, 23.

(7) Ho Choi, S.; Kim, B.; Frisbie, C. D. Science 2008, 320, 1482.

(8) Nijhuis, C. A.; Reus, W. F.; Whitesides, G. M. J. Am. Chem. Soc. 2009, 131, 17814.

(9) Nijhuis, C. A.; Reus, W. F.; Whitesides, G. M. J. Am. Chem. Soc. 2010, 132, 18386.

(10) Wang, G.; Kim, T.-W.; Lee, T. J. Mater. Chem. 2011, 21, 18117.

(11) Simeone, F. C.; Yoon, H. J.; Thuo, M. M.; Barber, J. R.; Smith, B.; Whitesides, G. M. J. Am. Chem. Soc. 2013, 135, 18131.

(12) Simmons, J. G. J. Appl. Phys. 1963, 34, 1793.

(13) Simmons, J. G. J. Appl. Phys. 1963, 34, 2581.

(14) Cahen, D.; Kahn, A. Adv. Mater. 2003, 15, 271.

(15) Haick, H.; Ambrico, M.; Ligonzo, T.; Tung, R. T.; Cahen, D. J. Am. Chem. Soc. 2006, 128,6854 .

(16) Tao, N. J. Nat. Nanotechnol. 2006, 1, 173.

(17) Heimel, G.; Romaner, L.; Zojer, E.; Bredas, J.-L. Acc. Chem. Res. 2008, 41, 721.

(18) Aradhya, S. V.; Venkataraman, L. Nat. Nanotechnol. 2013, 8, 399.

(19) Liao, K.-C.; Yoon, H. J.; Bowers, C. M.; Simeone, F. C.; Whitesides, G. M. Angew. Chem. Int. Ed. 2014, 53, 3889.

(20) Bowers, C. M.; Liao, K.-C.; Yoon, H. J.; Rappoport, D.; Baghbanzadeh, M.; Simeone, F. C.; Whitesides, G. M. Nano Lett. 2014, 14, 3521. 
(21) Yoon, H. J.; Bowers, C. M.; Baghbanzadeh, M.; Whitesides, G. M. J. Am. Chem. Soc. 2014, 136, 16.

(22) Yoon, H. J.; Shapiro, N. D.; Park, K. M.; Thuo, M. M.; Soh, S.; Whitesides, G. M. Angew. Chem. Int. Ed. 2012, 51, 4658.

(23) Thuo, M. M.; Reus, W. F.; Simeone, F. C.; Kim, C.; Schulz, M. D.; Yoon, H. J.;

Whitesides, G. M. J. Am. Chem. Soc. 2012, 134, 10876.

(24) Yoon, H. J.; Liao, K.-C.; Lockett, M. R.; Kwok, S. W.; Baghbanzadeh, M.;

Whitesides, G. M. J. Am. Chem. Soc. 2014, 136, 17155.

(25) Baghbanzadeh, M.; Simeone, F. C.; Bowers, C. M.; Liao, K.-C.; Thuo, M.;

Baghbanzadeh, M.; Miller, M. S.; Carmichael, T. B.; Whitesides, G. M. J. Am. Chem. Soc. 2014, 136, 16919.

(26) Nurbawono, A.; Liu, S.; Nijhuis, C. A.; Zhang, C. J. Phys. Chem. C 2015, doi: $10.1021 / \mathrm{jp} 5116146$.

(27) Chidsey, C. E. D.; Loiacono, D. N. Langmuir 1990, 6, 682.

(28) Fukushima, H.; Seki, S.; Nishikawa, T.; Takiguchi, H.; Tamada, K.; Abe, K.;

Colorado, R.; Graupe, M.; Shmakova, O. E.; Lee, T. R. J. Phys. Chem. B 2000, 104, 7417.

(29) Beebe, J. M.; Moore, H. J.; Lee, T. R.; Kushmerick, J. G. Nano Lett. 2007, 7, 1364.

(30) Graupe, M.; Takenaga, M.; Koini, T.; Colorado, R.; Lee, T. R. J. Am. Chem. Soc. 1999, $121,3222$.

(31) Kirsch, P. In Modern Fluoroorganic Chemistry; Wiley-VCH Verlag GmbH \& Co. KGaA: 2005, p 1 .

(32) O'Hagan, D. Chem. Soc. Rev. 2008, 37, 308.

(33) Reed, T. M. J. Phys. Chem. 1955, 59, 428.

(34) Lemal, D. M. J. Org. Chem. 2004, 69, 1.

(35) Gary, J. T.; Pickett, L. W. J. Chem. Phys. 1954, 22, 1266.

(36) Colorado, R.; Lee, T. R. Langmuir 2003, 19, 3288.

(37) Hotchkiss, P. J.; Jones, S. C.; Paniagua, S. A.; Sharma, A.; Kippelen, B.;

Armstrong, N. R.; Marder, S. R. Acc. Chem. Res. 2011, 45, 337.

(38) Wang, H.; Gomez, E. D.; Guan, Z.; Jaye, C.; Toney, M. F.; Fischer, D. A.; Kahn, A.; Loo, Y.-L. J. Phys. Chem. C 2013, 117, 20474. 
(39) McClain, W. E.; Florence, P. R.; Shu, A.; Kahn, A.; Schwartz, J. Org. Electron 2013, 14, 411 .

(40) DiBenedetto, S. A.; Facchetti, A.; Ratner, M. A.; Marks, T. J. Adv. Mater. 2009, $21,1407$.

(41) Ma, H.; Yip, H.-L.; Huang, F.; Jen, A. K. Y. Adv. Funct. Mater. 2010, 20, 1371.

(42) Dalvi, V. H.; Rossky, P. J. Proc. Natl. Acad. Sci. U.S.A. 2010, 107, 13603.

(43) Yuan, Y.; Yam, C. M.; Shmakova, O. E.; Colorado, R.; Graupe, M.; Fukushima, H.; Moore, H. J.; Lee, T. R. J. Phys. Chem. C 2011, 115, 19749.

(44) Alves, C. A.; Porter, M. D. Langmuir 1993, 9, 3507.

(45) Liu, G. y.; Fenter, P.; Chidsey, C. E. D.; Ogletree, D. F.; Eisenberger, P.;

Salmeron, M. J. Chem. Phys. 1994, 101, 4301.

(46) Tamada, K.; Ishida, T.; Knoll, W.; Fukushima, H.; Colorado, R.; Graupe, M.;

Shmakova, O. E.; Lee, T. R. Langmuir 2001, 17, 1913.

(47) de Boer, B.; Hadipour, A.; Mandoc, M. M.; van Woudenbergh, T.; Blom, P. W. M. Adv. Mater. 2005, 17, 621 .

(48) Cho, C.-P.; Tao, Y.-T. Langmuir 2007, 23, 7090.

(49) Yu, S.-Y.; Huang, D.-C.; Chen, Y.-L.; Wu, K.-Y.; Tao, Y.-T. Langmuir 2011, 28, 424.

(50) Wu, K.-Y.; Yu, S.-Y.; Tao, Y.-T. Langmuir 2009, 25, 6232.

(51) Weiss, E. A.; Kaufman, G. K.; Kriebel, J. K.; Li, Z.; Schalek, R.; Whitesides, G. M. Langmuir 2007, 23, 9686.

(52) Wan, A.; Jiang, L.; Sangeeth, C. S. S.; Nijhuis, C. A. Adv. Funct. Mater. 2014, 24, 4442.

(53) Wimbush, K. S.; Fratila, R. M.; Wang, D.; Qi, D.; Liang, C.; Yuan, L.; Yakovlev, N.; Loh, K. P.; Reinhoudt, D. N.; Velders, A. H.; Nijhuis, C. A. Nanoscale 2014, 6, 11246.

(54) Barber, J. R.; Yoon, H. J.; Bowers, C. M.; Thuo, M. M.; Breiten, B.; Gooding, D. M.; Whitesides, G. M. Chem. Mater. 2014, 26, 3938.

(55) Akkerman, H. B.; Naber, R. C. G.; Jongbloed, B.; van Hal, P. A.; Blom, P. W. M.; de Leeuw, D. M.; de Boer, B. Proc. Natl. Acad. Sci. U.S.A. 2007, 104, 11161.

(56) Engelkes, V. B.; Beebe, J. M.; Frisbie, C. D. J. Am. Chem. Soc. 2004, 126, 14287. 
(57) Lee, S.; Puck, A.; Graupe, M.; Colorado, R.; Shon, Y.-S.; Lee, T. R.; Perry, S. S. Langmuir 2001, 17, 7364.

(58) Levine, I.; Weber, S. M.; Feldman, Y.; Bendikov, T.; Cohen, H.; Cahen, D.; Vilan, A. Langmuir 2011, 28, 404.

(59) Beebe, J. M.; Engelkes, V. B.; Miller, L. L.; Frisbie, C. D. J. Am. Chem. Soc. 2002, 124, 11268.

(60) Wang, G.; Kim, T.-W.; Jang, Y. H.; Lee, T. J. Phys. Chem. C 2008, 112, 13010. 
Figure 1. (a) A cartoon representing junctions comprising SAMs of $\mathrm{HO}_{2} \mathrm{C}\left(\mathrm{CH}_{2}\right)_{\mathrm{n}} \mathrm{CH}_{3}$, $\mathrm{HO}_{2} \mathrm{C}\left(\mathrm{CH}_{2}\right)_{2}\left(\mathrm{CF}_{2}\right)_{\mathrm{n}-2} \mathrm{CF}_{3}$, and $\mathrm{HO}_{2} \mathrm{C}\left(\mathrm{CF}_{2}\right)_{n} \mathrm{CF}_{3}(\mathrm{n}=2,4,6,8)$. (b) A plot of log-current density $(\log |J|)$ against the number of methylene $\left(\mathrm{CH}_{2}\right)$ and/or difluoromethylene $\left(\mathrm{CF}_{2}\right)$ groups at $-0.5 \mathrm{~V}$. The values of $\beta$ for $\mathrm{CH}_{2}$ and $\mathrm{CF}_{2}$ are similar; the numbers are inserted in the figure. The intercepts at the $y$ axis indicate the extrapolated log-current densities $\left(\log \left|J_{0}\right|\right)$ for $\mathrm{HO}_{2} \mathrm{C}\left(\mathrm{CH}_{2}\right)_{\mathrm{n}} \mathrm{CH}_{3}\left(\boldsymbol{\varpi}, \log \left|J_{0}\right|=2.8 \pm 0.2\right), \mathrm{HO}_{2} \mathrm{C}\left(\mathrm{CH}_{2}\right)_{2}\left(\mathrm{CF}_{2}\right)_{\mathrm{n}-2} \mathrm{CF}_{3}\left(\boldsymbol{\Xi}, \log \left|J_{0}\right|=1.5 \pm 0.3\right)$, and $\mathrm{HO}_{2} \mathrm{C}\left(\mathrm{CF}_{2}\right)_{\mathrm{n}} \mathrm{CF}_{3}\left(\square, \log \left|J_{0}\right|=1.3 \pm 0.2\right)$, when $\mathrm{n}=0$.

a
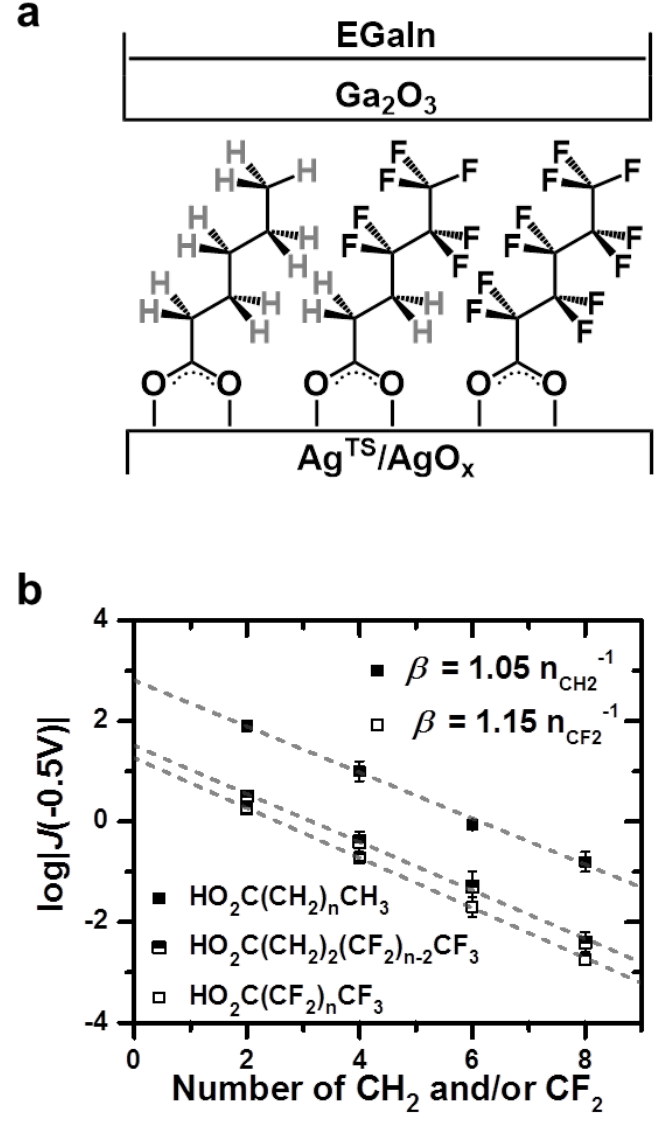
Figure 2. Histograms of $\log |J(-0.5 \mathrm{~V})|$ data derived from $\mathrm{HO}_{2} \mathrm{C}\left(\mathrm{CH}_{2}\right)_{\mathrm{n}}\left(\mathrm{C}_{6} \mathrm{H}_{4}\right)_{\mathrm{m}} \mathrm{T}$, where $\mathrm{T}=\mathrm{CH}_{3}$ (black) and $\mathrm{CF}_{3}$ (blue): (a) $\mathrm{HO}_{2} \mathrm{C}\left(\mathrm{C}_{6} \mathrm{H}_{4}\right) \mathrm{T}$, (b) $\mathrm{HO}_{2} \mathrm{C}\left(\mathrm{CH}_{2}\right)_{2}\left(\mathrm{C}_{6} \mathrm{H}_{4}\right) \mathrm{T}$, and (c) $\mathrm{HO}_{2} \mathrm{C}\left(\mathrm{C}_{6} \mathrm{H}_{4}\right)_{2} \mathrm{~T}$. The dotted line aligns $J(-0.5 \mathrm{~V})$ at $1.0 \mathrm{~A} / \mathrm{cm}^{2}$.

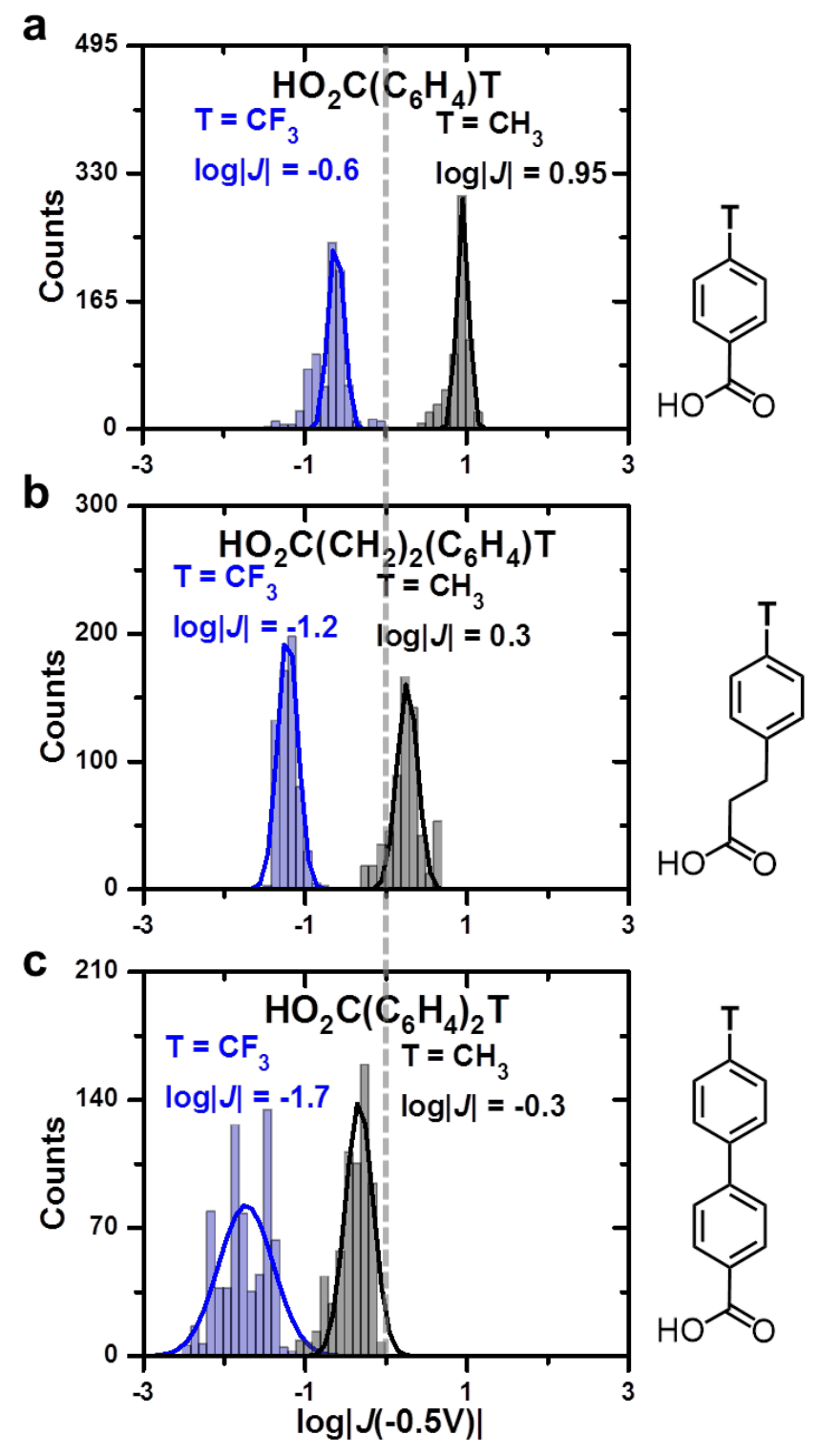


Figure 3. (a) A cartoon representation of the $\mathrm{Ag}^{\mathrm{TS}} \mathrm{O}_{2} \mathrm{C}\left(\mathrm{CH}_{2}\right)_{\mathrm{n}}\left(\mathrm{C}_{6} \mathrm{H}_{4}\right) \mathrm{T} / / \mathrm{Ga}_{2} \mathrm{O}_{3} / \mathrm{EGaIn}$ junction, where $\mathrm{n}=0,2,4$ and $\mathrm{T}=\mathrm{H}$ or $\mathrm{F}$. (b) A plot of $\log$-current density $(\log |J|)$ against the number of methylene $\left(\mathrm{CH}_{2}\right)$ groups at $-0.5 \mathrm{~V}$. The intercepts at the $y$ axis indicate $\log \left|J_{0}\right|$ for $\omega$-phenylalkanoates $\left(1.5 \pm 0.2 \mathrm{~A} / \mathrm{cm}^{2}\right)$ and $\omega$-(4-fluorophenyl)-alkanoates $\left(0.3 \pm 0.2 \mathrm{~A} / \mathrm{cm}^{2}\right)$ when $\mathrm{n}=0$. The separation between two lines suggests that the presence of fluorine at the SAM $/ / \mathrm{Ga}_{2} \mathrm{O}_{3}$ interface reduces the value of $J_{0}$, and the tunneling current, by a factor of 16 .

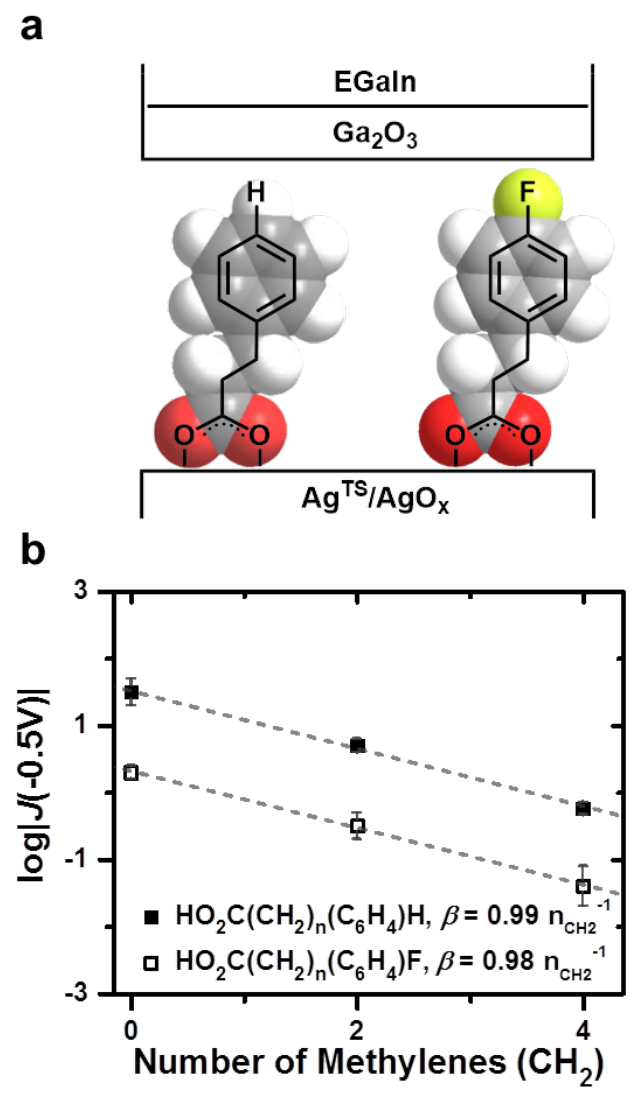


Figure 4. Histograms of $\log |J(-0.5 \mathrm{~V})|$ data derived from $\mathrm{HO}_{2} \mathrm{C}\left(\mathrm{CH}_{2}\right)_{\mathrm{n}}\left(\mathrm{C}_{6} \mathrm{H}_{4}\right) \mathrm{T}$, where $\mathrm{T}=\mathrm{H}$ (black) and F (blue): (a) $\mathrm{HO}_{2} \mathrm{C}\left(\mathrm{C}_{6} \mathrm{H}_{4}\right) \mathrm{T}$, (b) $\mathrm{HO}_{2} \mathrm{C}\left(\mathrm{CH}_{2}\right)_{2}\left(\mathrm{C}_{6} \mathrm{H}_{4}\right) \mathrm{T}$, and (c) $\mathrm{HO}_{2} \mathrm{C}\left(\mathrm{CH}_{2}\right)_{4}\left(\mathrm{C}_{6} \mathrm{H}_{4}\right) \mathrm{T}$. The dotted line aligns $J(-0.5 \mathrm{~V})$ at $1.0 \mathrm{~A} / \mathrm{cm}^{2}$.

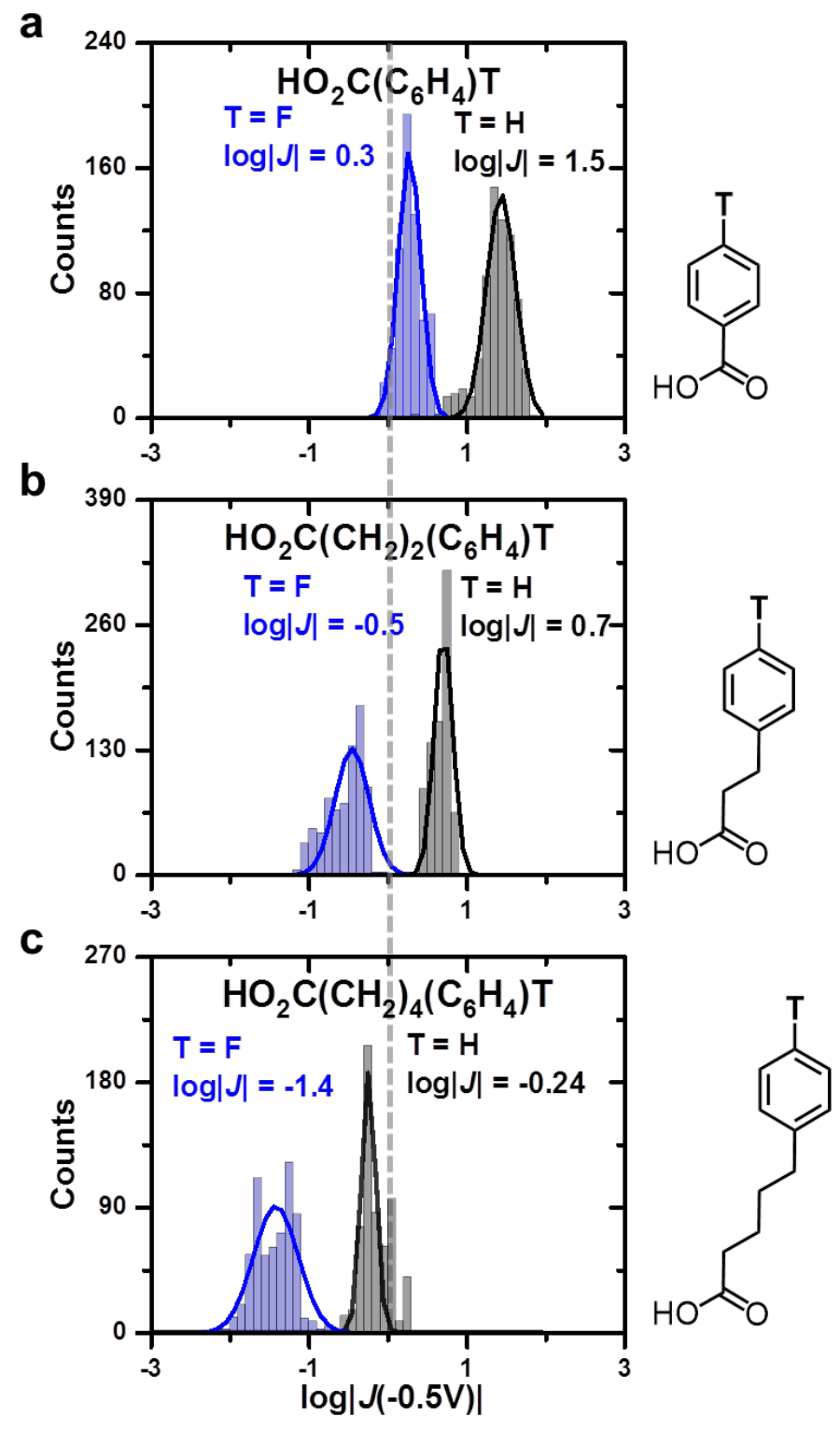


Table 1. Summary of current densities $\left(\mathrm{A} / \mathrm{cm}^{2}\right)$ derived from EGaIn-based junctions comprising

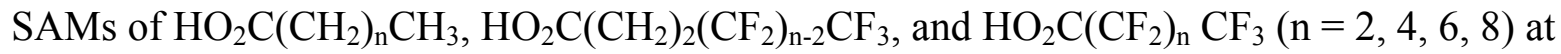
$-0.5 \mathrm{~V}$. A linear-least square fit for each series of SAMs (Figure 1) yielded a slope and an intercept at the $y$ axis; the former provides the attenuation factor, $\beta$, of the repeating units and the intercept represents the value of the $\log \left|J_{0}\right|$ when $\mathrm{n}=0$. We adapted the result of junction measurements of $\mathrm{HO}_{2} \mathrm{C}\left(\mathrm{CH}_{2}\right)_{\mathrm{n}} \mathrm{H}$ from ref. 19.

\begin{tabular}{cccc}
\hline & $\mathrm{HO}_{2} \mathrm{C}\left(\mathrm{CH}_{2}\right)_{\mathrm{n}} \mathrm{CH}_{3}$ & $\mathrm{HO}_{2} \mathrm{C}\left(\mathrm{CH}_{2}\right)_{2}\left(\mathrm{CF}_{2}\right)_{\mathrm{n}-2} \mathrm{CF}_{3}$ & $\mathrm{HO}_{2} \mathrm{C}\left(\mathrm{CF}_{2}\right)_{\mathrm{n}} \mathrm{CF}_{3}$ \\
\hline $\mathrm{n}$ & $\log |J| \pm \sigma_{\log }$ & $\log |J| \pm \sigma_{\log }$ & $\log |J| \pm \sigma_{\log }$ \\
\hline 2 & $1.9 \pm 0.1$ & $0.5 \pm 0.1$ & $0.24 \pm 0.06$ \\
4 & $1.0 \pm 0.2$ & $-0.4 \pm 0.2$ & $-0.72 \pm 0.07$ \\
6 & $-0.06 \pm 0.06$ & $-1.3 \pm 0.3$ & $-1.7 \pm 0.2$ \\
8 & $-0.8 \pm 0.2$ & $-2.4 \pm 0.2$ & $-2.75 \pm 0.09$ \\
\hline 0 & $\log \left|J_{0}\right|=2.8 \pm 0.2$ & $\log \left|J_{0}\right|=1.5 \pm 0.3$ & $\log \left|J_{0}\right|=1.3 \pm 0.2$ \\
\hline & $\beta=1.05 \pm 0.02 \mathrm{n}_{\mathrm{CH}_{2}}{ }^{-1}$ & $\beta=1.11 \pm 0.03 \mathrm{n}_{\mathrm{CH}_{2} / \mathrm{CF}_{2}}{ }^{-1}$ & $\beta=1.15 \pm 0.02 \mathrm{n}_{\mathrm{CF}_{2}}{ }^{-1}$ \\
\hline
\end{tabular}




\section{TOC}
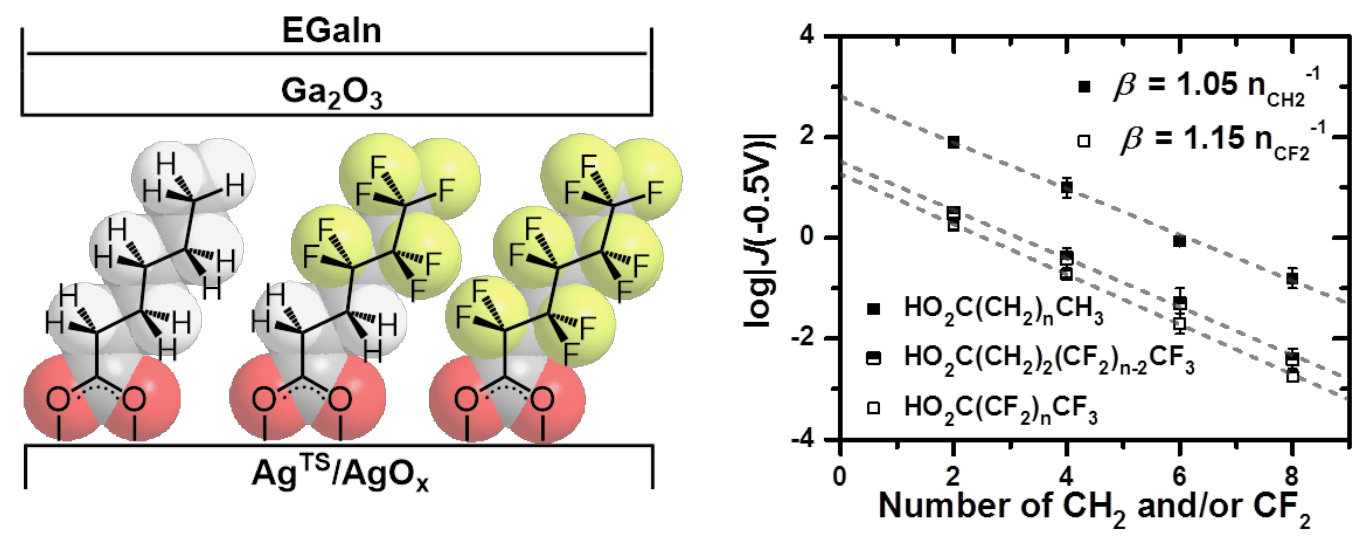